\title{
PARADOKS PENERAPAN GOOD GOVERNANCE DI INDONESIA: SUATU TINJAUAN KRITIS MP3EI
}

\author{
Aspin Nur Arifin Rivai ${ }^{1}$, Gema Ramadhan Bastari ${ }^{2}$ \\ ${ }^{1}$ Universitas Islam Negeri Alauddin \\ ${ }^{2}$ Universitas Indonesia \\ Email: askaspin@gmail.com ${ }^{1}$, gemarbastari@gmail.com²
}

\begin{abstract}
Abstrak
Artikel ini akan menjelaskan betapa bermasalahnya penerapan konsep tata kelola yang baik (good governance) bagi masyarakat Indonesia. Konsep ini bermula sebagai preskripsi yang berasal dari lembaga keuangan internasional guna memperbaiki persoalan pembangunan di negara berkembang, sekaligus menyuguhkan betapa konsep ini membawa janji kesejahtraan. Pada beberapa pekembangganya, justru menjadi instrument kontrol untuk mendikte kebijakan negara berkembang. Artikel ini berpendapat bahwa tata kelola yang baik sebenarnya merupakan agenda neoliberalisme yang berupaya merekayasa lanskap ekonomi suatu negara sehingga dapat negara tersebut dapat menyesuaikan dengan mekanisme pasar global. Hal ini dapat dibuktikan dengan memproblematisasi konsep tata kelola yang baik sebagaimana konsep ini memiliki kesamaaan dengan beberapa lembaga besar, sepertu PBB, UNDP, IMF, World Bank, dan OECD. Pembuktian lainnya akan ditunjukkan melalui MP3EI yang dirancang atas nama komitmen terhadap prinsip tata kelola yang baik. Artikel ini menemukan bahwa implementasi MP3EI hanya menguntungkan bagi pihak penguasa dan perusahaan besar, tetapi justru menumbalkan masyarakat Indonesia. Corak ini berwujud paradox, sebab tata kelola yang baik didesain untuk membuat negara menjadi sejahtra, justru rakyat harus mendapatkan penyiksaan dari logika pembangunan tersebut.
\end{abstract}

Kata Kunci:

Good Governance; Governmentality, Neoliberalisme, Demokrasi

\begin{abstract}
This paper explained how harmful the implementation of good governance has been to the well-being of Indonesian people. The concept of good governance starts as a prescription from international finance institution to fix the economic condition of developing state and bring them towards prosperity. On recent developments, good governance has instead become an instrument of control to dictate the policy-making of developing state. This paper argued that good governance actually represents neoliberalism agenda which seeks to engineer the economic landscape of a certain country so it can be more compatible to the needs of global market. This would be proven by problematizing the concept of good governance as well as analysis on the definition of good governance provided by five of its main proponents: UN, UNDP, $I M F$, World Bank and OECD. Further evidence will be shown through case study in the implementation of Masterplan for Acceleration and Expansion of Indonesia's Economic
\end{abstract}


Development (MP3EI) which was made in the name of commitment to good governance principle. This paper found that the implementation MP3EI was only advantageous for businessmen and big corporates but tormenting the people of Indonesia. This was a paradox since good governance which is supposed to make a prosperous state instead tormenting the people that should be the state's main constituent.

Keywords:

Good Governance; Governmentality, Neoliberalism, Democracy

\section{Pendahuluan}

"There is nothing either good or bad, but thinking makes it so." -William Shakespeare

Tata kelola yang baik (good governance) adalah konsep yang sangat ambigu. Konsep ini bermula dari laporan World Bank di Afrika pada tahun 1992 yang dinilai mengalami 'krisis tata kelola'. World Bank menilai bahwa kemiskinan di negara-negara Afrika disebabkan oleh ketidakmampuan pemerintah untuk mengelola sumber dayanya akibat korupsi, ketiadaan demokrasi dan ketiadaan transparansi. ${ }^{1}$

World Bank kemudian menilai bahwa apa yang terjadi di Afrika adalah tata kelola yang 'buruk' dan mendefinisikan bahwa tata kelola yang 'baik' adalah: penggunaan kekuasaan untuk mengatur sumber daya ekonomi dan sosial negara untuk kepentingan pembangunan. Hal ini dapat dimungkinkan dengan menerapkan lima prinsip utama dari tata kelola yang baik: (1) akuntabilitas; (2) efektifitas; (3) regulasi minimum; (4) aturan hukum; dan (5) independensi peradilan. Dengan menerapkan prinsip-prinsip tersebut, World Bank berargumen bahwa suatu negara akan mencapai kemajuan dan kesejahteraan. ${ }^{2}$ Akan tetapi, praktek good governance yang terjadi di berbagai negara menunjukkan bahwa segalanya tidak sesederhana yang dikatakan World Bank.

Di Indonesia, jutaan warga harus tercerabut dari tempat tinggalnya karena tanah mereka diputuskan sebagai wilayah pembangunan infrastruktur, seperti jalan tol, waduk, apartemen dan lain-lain. Warga di Kampung Pulo, Jatigede, Cilamaya, dan masih banyak lagi, tidak dapat pulang ke rumah di mana mereka dilahirkan. Mereka

1 Thandike Mkandawire, "Good Governance: The Itinerary of an Idea" dalam Development in Practice, Vol. 17, No 4/5 (2007), h. 679.

2 Arif Budi Rahman, “Good Governance: Challenge and Prospect for Indonesia”dalam Widyariset, Vol. 14, No. 1 (2011), h. 84. 
tidak dapat lagi bertani karena sawah mereka ditenggelamkan untuk membangun waduk. Hanya untuk mendapat ganti rugi yang layak, mereka harus berdebat dan bersengketa dengan pemerintah atau industri ekstraktif yang menempati tanah mereka ${ }^{3}$. Mereka adalah korban dari Masterplan Percepatan dan Perluasan Pembangunan Ekonomi Indonesia (MP3EI), sebuah program Pemerintah Indonesia yang dilakukan atas nama 'komitmen kepada penerapan good governance' dan disponsori oleh World Bank. $^{4}$

Sejumlah lembaga hak asasi manusia (HAM) mengungkapkan, bahwa program tersebut telah abai terhadap hak-hak fundamental yang dimiliki warga yang tinggal di lahan yang dibebaskan untuk pembangunan infrastruktur. ${ }^{5}$ Pertanyaan penting yang harus diajukan dalam situasi ini adalah: jika benar bahwa tata kelola yang baik akan mengantarkan suatu bangsa pada kemajuan dan kesejahteraan, lantas mengapa hal tersebut harus mensyaratkan penderitaan dan eksploitasi masyarakat? Pertanyaan ini layak diajukan, sebab akan menguji apakah out-put kebijakan elit bermasalah secara praktis dikarenakan konsep dan resep pembangunan melalui tata kelola yang baik telah bermasalah semenjak diluncurkan oleh World Bank ataukah sebaliknya?

\section{Keterkaitan antara Good Governance dan Agenda Neoliberalisme}

"A text is not a text unless it hides from the first comer, from the first glance, the law of its composition and the rules of its game." -Jacques Derrida

Adalah naif jika kita hanya memahami konsep good governance secara harfiah sebagai sesuatu yang 'baik' sesuai namanya. Sebagaimana dikatakan Derrida, sebuah teks selalu menyembunyikan suatu aturan yang tidak dapat dipahami secara sekilas. Pertanyaan kritis yang harus pertama kali diajukan untuk menginterogasi konsep ini adalah: baik untuk siapa? Pertanyaan ini dengan sendirinya mengindikasikan, bahwa terdapat muatan politik yang terkandung di dalam konsep good governance.

\footnotetext{
3 Tito Dirhantoro, "MP3EI Timbulkan Masalah Hingga Ke Daerah" dalam http://geotimes.co.id/mp3ei-timbulkan-masalah-hingga-daerah/ diakses 16 Mei 2018.

4 World Bank, "World Bank Approves New Financing for Priority Reforms in Indonesia" dalam http://geotimes.co.id/mp3ei-timbulkan-masalah-hingga-daerah/diakses 16 Mei 2018.

5 Febrian, "Kontras: MP3EI Dapat Berdampak pada Pelanggaran HAM" dalam http://nasional.kompas.com/read/2014/06/12/1635570/Kontras.MP3EI.Dapat.Berdampak.pada. Pelanggaran.HAM diakses 16 Mei 2018.
} 
Dalam hal ini, riset maupun praktik mengenai konsep good governance telah tumbuh menjadi diskursus kontemporer yang dimuntahkan oleh rezim internasional. Akibatnya, konsep ini menjadi primadona dihadapan komunitas internasional. Meski begitu, good governance dalam perdebatan yang lebih utuh justru menghasilkan berbagai ruang-ruang paradoks. Atas dasar itu, tulisan ini pertama-tama melacak apakah konsep good governance telah cacat secara konseptual atau sebaliknya.

Penulis memetakan terdapat dua garis besar konstruksi intelektual mengenai konsep good governance. Literatur pertama berfokus pada ukuran dan penilaian kualitas tata pemerintahan di negara-negara tertentu dan lintas-nasional. ${ }^{6}$ Selanjutnya, perhatian analisis lain tertuju pada hubungan antara tata pemerintahan dengan pertumbuhan ekonomi. $^{7}$

Meski literatur di atas memandang konsep ini sebagai instrumen untuk mengatasi persoalan-persoalan pembangunan - para penentang konsep ini telah mengklasifikasikan bahwa good governance bersifat polemis dan sarat akan kepentingan politik yang dibawa oleh negara dan institusi pendonor. Asesmen mereka

${ }^{6}$ Secara umum, studi yang telah ada mengkaji tentang pengalaman-pengalaman, khusunya Negara berkembang dalam mempraktikkan konsep good governance. Studi-studi itu lantas menarik simpulan bahwa terdapat beberapa tantangan mendasar dari pelaksanaan konsep ini, misalnya bantuan penyelenggaraan good governance hanya mendorong penciptaan lembaga-lembaga administratif yang justru tidak dijalankan secara mandiri. Hal ini diakibatkan kuatnya rezim status quo dalam menjalankan otoritas bahkan mengganggu lembaga otonom. Sehingga celah intervensi semakin melebar. Akibatnya, kualitas kelembagaan dalam menjalankan tujuan good governance menjadi imaji. Lihat, Alex E. Fernandes Jilberto, "The Political Economy of Neoliberal Governance in Latin America: The Case of Chile" dalam Demmers, Jolle, Alex E.Fernández Jilberto dan Barbara Hogenboom (eds.), Good Governance in the Era of Global Neoliberalism (London: Routledge, 2004). 33-55. Juga David Chandler, "Good Governance Can Make Bad Government: A study of Iinternational Anti-Corruption Initiatives in Bosnia-Herzegovina" dalam Demmers, Jolle, Alex E.Fernández Jilberto dan Barbara Hogenboom (eds.), Good Governance in the Era of Global Neoliberalism (London: Routledge, 2004). 140-156. Kemudian, Thomas J. Lindblad, "The Economic Decolonisation of Indonesia: a Bird's-eye View", dalam Journal of Indonesian Social Sciences and Humanities, Vol. 4 (2011). h. 1-20. Kemudian, Christiane Arndt Oman \& Charles, Uses and Abuses of Governance Indicators (Paris: OECD, 2006). Lihat juga, Carmen Apaza, "Measuring Governance and Corruption through the Worldwide Governance Indicators: Critiques, Responses, and Ongoing Scholarly Discussion", dalam Political Science and Politics, Vol. 42, No. 1 (2009), h. 118. Terakhir, M.A. Thomas, "What Do the Worldwide Governance Indicators Measure?", dalam The European Journal of Development Research, Vol. 22, No. 1 (2010), h. 31-54.

7 Penelitian lainnya cenderung bersifat kuantitas dalam menelaah good governance. Artinya, capaian konsep ini dapat dikatakan terjadi apabila memenuhi beberapa variable dan indicator pengukuran pada kebijakan dan institusi. Beberapa penelitian yang telah ada, misalnya World Bank, Sub-Sabaran Africa. From Crisis to Sustainable Growth: A Long-Term Perspective Study (Washington DC: World Bank, 1989). Kemudian, Daniel Kaufman, Aart Kraay, \& Pablo Zoido, "Governance Matters.” World Bank Policy Research Working Paper No. 2196 (1999). Lihat juga Philip Keefer, "“Governance.” Dalam, Todd Landman dan Neil Robinson, The SAGE Handbook of Comparative Politics . (London: Sage, 2009). h. 439-462. Kemudian, Al-Bassam, "The Relationship Between Governance and Economic Growth During Times of Crisis." dalam European Journal of Sustainable Development Vol. 2, No. 4 (2013). h. 1-18. Terakhir, Bichaka Fayissa \& Christian Nsiah. "The Impact of Governance on Economic Growth in Africa." dalam The Journal of Developing Areas Vol. 47, No. 1 (2013), h. 91-108. 
berlangsung di negara-negara penerima bantuan yang berpendapat bahwa penggunaan kriteria pembangunan dalam alokasi bantuan asing secara efektif telah memperkenalkan kondisionalitas politik dan menanamkan praktik demokrasi liberal Barat. ${ }^{8}$

David Booth dalam tulisannya menunjukkan bahwa agenda good governance adalah preskripsi yang sangat lemah untuk kebijakan, sebab bersifat tidak realistis, dan tidak selaras dengan rangkaian historis dan masalah pembangunan. ${ }^{9}$ Hal yang sama ditunjukkan oleh Matt Andrews dengan mencatat bahwa model umum dari efektivitas tata pemerintahan yaitu memberi tahu kepada negara berkembang mengenai preskripsi pembangunan menjadi negara yang mapan dalam agenda pembangunan, dan gagasan good governance merupakan model terbaik dari tata pemerintahan. ${ }^{10}$

Terlepas dari pentingnya good governance bagi agenda pembangunan internasional - terdapat ambiguitas dari keterhubungan antara keduanya, sehingga menghasilkan sebuah pertanyaan esensial, yaitu: apakah arti sesungguhnya dari good governance? Sejauh ini, konsep ini telah dihembuskan oleh berbagai institusi dan negara pendonor sehingga menghasilkan jawaban-jawaban yang berbeda.Perbedaan ini bergantung pada pandangan mereka dalam mengklasifikasikan keadaan "baik" dalam suatu tata pemerintahan. Setidaknya terdapat lima intitusi internasional yang acapkali mempromosikan good governance di negara-negara yang mengalami persoalan pembangunan, yaitu Persatuan Bangsa-Bangsa (PBB), United Nations Development Program (UNDP), Bank Dunia, International Monetary Fund (IMF), dan Organization for Economic Coperation and Development (OECD).

Tabel 1. Definisi Good Governance dari Institusi Internasional

\begin{tabular}{|l|l|}
\hline PBB & $\begin{array}{l}\text { Good governance merupakan agenda global yang mempromosikan } \\
\text { kesetaraan, partisipasi, pluralisme, transparansi, akuntabilitas dan }\end{array}$ \\
& $\begin{array}{l}\text { penegakan aturan hukum dalam roda pemerintahan secara efektif, } \\
\text { efisien, dan berkelanjutan. Dalam menerjemahkan prinsip-prinsip }\end{array}$ \\
\hline
\end{tabular}

8 Ved P. Nanda, "The Good Governance Concept Revisited." dalam The Annals of the American Academy of Political and Social Science Vol. 603 (2006), h. 269-283.

9 David Booth, “Aid, Institutions and Governance: What Have We Learned?" dalam Development Policy Review Vol. 29, No. 1 (2010), h. 5-26.

10 Matt Andrews, "The Good Governance Agenda: Beyond Indicators without Theory" dalam Oxford Development Studies, Vol. 36, No. 4 (2008), h. 379-407. 


\begin{tabular}{|c|c|}
\hline & $\begin{array}{l}\text { tersebut, penulis melihat bahwa sasaran utama dari implementasi good } \\
\text { governance ialah penyelenggaraan roda pemerintahan secara demokratis } \\
\text { dengan menjalankan pemilu secara bebas, akuntabel, dan adil. }\end{array}$ \\
\hline UNDP & $\begin{array}{l}\text { Good governance mengacu pada sistem pemerintahan yang kapabel, } \\
\text { responsif, inklusif, dan transparan. UNDP memberikan pengistilahan } \\
\text { konsep good governance sebagai democratic governance di mana } \\
\text { melibatkan partisipasi politik secara inklusif }\end{array}$ \\
\hline $\begin{array}{l}\text { Bank } \\
\text { Dunia }\end{array}$ & $\begin{array}{l}\text { Implementasi good governace menerangkan fungsi penyelenggaraan } \\
\text { roda pemerintahan secara efektif, dan menggapai pertumbuhan ekonomi. } \\
\text { Bank Dunia memiliki patokan dasar dalam menjelaskan konsep good } \\
\text { governance yang mengacu pada empat elemen dasar, yaitu manajemen } \\
\text { sektor publik, akuntabilitas dalam layanan sektor publik, Kerangka } \\
\text { hukum, dan transparansi }\end{array}$ \\
\hline IMF & $\begin{array}{l}\text { Good governance merupakan hal yang penting bagi seluruh negara } \\
\text { dalam menyelenggarakan suatu "tahap pembangunan". konsep ini } \\
\text { sebagai pendekatan yang dikawal oleh IMF untuk berkonsentrasi pada } \\
\text { aspek-aspek yang saling interdependen dengan kebijakan makro- } \\
\text { ekonomi - yaitu, transparansi neraca keuangan pemerintah, efektivitas } \\
\text { manajemen sumber daya publik, dan stabilitas dan transparansi ekonomi } \\
\text { dan regulasi untuk aktivitas sektor privat }\end{array}$ \\
\hline OECD & $\begin{array}{l}\text { Institusi pendonor ini kerapkali menamakan good governance sebagai } \\
\text { public governance, di mana mengacu pada enam elemen dasar, yaitu } \\
\text { akuntabilitas, transparansi, efisiensi dan efektivitas, responsivitas, visi } \\
\text { yang terbentang, dan aturan hukum }\end{array}$ \\
\hline
\end{tabular}

Sumber: Kompilasi penulis dari berbagai sumber.

Secara keseluruhan institusi-institusi di atas telah mendefinisikan bahwa suatu tata pemerintahan dapat dikatakan "baik" apabila meliputi beberapa komponen dasar, yaitu: (1) representasi dan demokrasi; (2) HAM; (3) aturan hukum (rule of law), (4) manajemen publik secara efisien dan efektif; (5) transparansi dan akuntabilitas; (6) objektivitas pembangunan; dan (7) berbagai macam kebijakan ekonomi dan politik. 
Jika diuraikan lebih mendalam, komponen-komponen di masing-masing institusi terkesan bermasalah di mana ekspektasi aransemen untuk mengatasi persoalanpersoalan pembangunan, namun secara realitas lebih diaplikasikan sesuai dengan logika dan praktik sistem demokrasi liberal atau neoliberal. Persoalan lebih ekstrim lagi ketika melihat diktum Bank Dunia justru tidak menghubungkan sistem pemerintahan dengan agenda pembangunan. Sebaliknya, Bank Dunia menyoroti manajemen publik yang efisien, efektif, akuntabel dan transparan, serta objektivitas pembangunan. Berikutnya, IMF justru tidak menyajikan sebuah definisi umum, namun secara eksplisit membingkai pembahasannya ke dalam komponen-komponen pemerintahan yang terkait dengan mandatnya yaitu menangani stabilitas makro-ekonomi.Terakhir, OECD memang menunjukkan beberapa komponen mengenai good governance.Jika kita cermati lebih kritis, maka komponen tersebut hanya menjelaskan arti sebuah sistem tata pemerintahan atau kinerja birokrasi - bukan sebagai wujud dari good governance dalam arti agenda pembangunan secara sesungguhnya.

Di sisi lain, kelima definisi di atas sebenarnya bersifat homogen, di mana atensi mereka hanya ada pada subjek pemerintah, sehingga kebijakan-kebijakan good governance lebih ditentukan oleh para pembuat kebijakan terlepas memfasilitasi peran masyarakat sipil. Kondisi ini kemudian menghasilkan pertanyaan esensial, jika good governance lebih dimunculkan sebagai agenda pembangunan - lantas mengapa atensinya hanya berwajah hierarkis dan struktural, padahal kegagalan pembangunan di hampir berbagai negara lebih banyaknya diikuti oleh aspek sistemik. Kondisi-kondisi ini kemudian semakin menunjukkan bahwa good governance secara konseptual dianggap rapuh dan polemis.

Promosi good governance yang telah difokuskan oleh lima institusi di atas pada gilirannya membentuk sebuah proses difusi dan pendalaman demokrasi liberal dengan nafas modernisasi ekonomi di negara-negara berkembang. Meski promosi ini memiliki ekspektasi meningkatkan kualitas ekonomi dan sosial, akan tetapi menghasilkan persoalan-persoalan pembangunan baru.

Di beberapa negara kawasan seperti Amerika Latin, Afrika, dan Asia yang mulai berkompromi menjalankan demokrasi elektoral justru menghadapi konflik-konflik horizontal, ketegangan antar-aktor politik, dan juga munculnya persoalan keamanan domestik. Sebagaimana dikatakan oleh Rita Abrahamsen, demokrasi baru di era pasca- 
Perang Dingin justru membawa permasalahan baru. Institusi keuangan internasional seperti World Bank berperan besar dalam situasi ini dengan memberikan dukungan modal dan tata kelola pemerintahan. Hal ini pada akhirnya menimbulkan ketergantungan dari negara-negara demokrasi baru tersebut kepada World Bank. ${ }^{11}$

Perubahan-perubahan yang dialami oleh negara berkembang semenjak menerima dan menjalankan promosi good governance telah menunjukkan suatu tren di mana politik domestik mulai patuh dengan logika-logika neoliberalisme. Transisi suatu negara yang mengalami kegagalan pembangunan akibat absensi penyelenggaraan sistem demokratis, pada akhirnya negara tersebut berkompromi untuk melaksanakan sistem pemerintahan sesuai logika neoliberalisme. ${ }^{12}$ Dalam hal ini, pemerintahan sesuai dengan beberapa komponen kunci good governance harus dipahami sebagai pemerintahan yang kompatibel terhadap agenda neoliberalisme. Tujuannya adalah agar negara tersebut semakin terbuka terhadap pasar global dan mengizinkan aset-aset nasionalnya untuk diprivatisasi dan dibeli oleh perusahaan-perusahaan multinasional. ${ }^{13}$

\section{Paradoks Penerapan Good Governance di Indonesia}

"Doublethink means the power of holding two contradictory beliefs in one's mind simultaneously, and accepting both of them."-George Orwell

Good governance merupakan istilah paling 'primadona' bagi agenda pembangunan di negara berkembang pasca-Perang Dingin. Francis Fukuyama, dalam tesisnya "The End of History"menyebutkan bahwa pertarungan paradigma politik global telah berakhir dengan kemenangan kapitalisme-neoliberal. ${ }^{14}$ Secara otomatis,

11 Rita Abrahamsen, Disciplining Democracy: Development Discourse and Good Governance in Africa (London: Zed Books, 2000).

${ }_{12}$ Neoliberalisme dalam konteks ekonomi adalah ideologi yang mempercayai bahwa kesejahteraan umat manusia dapat diraih dengan memberikan kebebasan seluas-luasnya bagi individu untuk berwiraswasta di dalam sebuah kerangka institusional yang bercirikan: dukungan atas hak milik pribadi dan pasar/perdagangan bebas. Neoliberal meyakini bahwa peran negara adalah sebatas menciptakan dan merawat kerangka institusional tersebut. Dengan kata lain, pasar harus dibiarkan berjalan sendiri, manusia harus dibiarkan mencari peruntungannya sendiri, negara tidak boleh mengintervensi. Untuk memahami lebih jelas, terdapat beberapa literatur yang cukup tuntas dalam menjelaskan makna sesungguhnya neoliberalisme. Namun, rujukan untuk mengenal introduksi neoliberalisme, lihat Dag Einar Thorsen, The Neoliberal Challenge: What is Neoliberalism? University of Oslo Working Paper, October 10, diunduh 8 April 2018, http://citeseerx.ist.psu.edu/viewdoc/download;jsessionid=233145141325B50946FE20B5D59769C2?doi=10 1.1.732.1184\&rep= rep1\&type $=$ pdf

13 Rhys Jerkins, "Structural Adjustment and Bolivian Industry" dalam The European Journal of Development Research, Vol. 9 No. 2 (1997).

${ }^{14}$ Francis Fukuyama, “The End of History?” Dalam, National Interst, Vol. 16 (1989). 
demokrai mengalami penyebaran proses difusi ke berbagai negara, khususnya negara dunia ketiga.

Indonesia merupakan salah satu bagian dari gugusan yang menghadapi difusi demokrasi. Perkembangan demokrasi di Indonesia mulai menguat seiring meningkatnya gerakan resistensi masyarakat sipil terhadap kepemimpinan Soeharto. Dalam hal ini, keberlangsungan difusi demokrasi dapat dikatakan melegitimasi eksistensi kelompok resisten. Selain itu, kepemimpinan Soeharto di awal tahun 1990an juga telah mengalami berbagai friksi, salah satunya yaitu dukungan politik yang semakin menurun dari kalangan militer dan ekonom. Imbasnya, kepercayaan yang makin berkurang seiring dengan krisis ekonomi tahun 1997 akhirnya memaksa Soeharto untuk mundur dari tampuk kekuasaannya. Momen tersebut tidak hanya mengganti struktur kekuasaan otoritarian, melainkan juga memberi jalan bagi munculnya wacana pembangunan baru di bawah skema good governance.

Pada masa awal pemerintahan Soeharto (1966-1980an), diskursus pembangunan Indonesia ditandai oleh beberapa hal, antara lain munculnya kapitalisme negara (developmental state) melalui proyek-proyek industrialisasi substitusi impor, keterbukaan ekonomi dan penanaman modal baik asing maupun domestik, pembenahan struktur dan aparatus negara, serta menguatnya rezim pembangunan yang berbasis pada perencanaan. Namun, pada tahun 1980an, 'oil boom' mulai surut dan dana yang mengalir tidak lagi sebesar tahun 1970an. Pada era ini, berdasarkan resep lembaga keuangan internasional dan didukung oleh para ekonom yang berhaluan liberal, pemerintah mulai memperkenalkan paket deregulasi keuangan yang menimbulkan perkembangan sektor finansial, liberalisasi sektor perdagangan, serta perubahan kebijakan industrialisasi menjadi model orientasi ekspor. ${ }^{15}$ Namun, skema-skema kebijakan ekonomi yang berbasis pada kerangka neo-institusional tersebut hancur setelah krisis ekonomi menerpa negara-negara Asia pada tahun 1997-1998.

Era Reformasi di Indonesia ditandai oleh munculnya satu diskursus dominan: good governance. Melalui satu paket bersama structural adjustment program dan beberapa mekanisme donor yang lain, good governance pada intinya menawarkan reformasi institusi negara yang berbasis pada "pembukaan dan perlindungan atas hak-

15 Vedi R. Hadiz \& Richard Robison. Reorganising Power in Indonesia: The Politics of Oligarchy in an Age of Markets (London: Routledge, 2004). 
hak individu, absennya korupsi, regulasi yang ramah-pasar, serta sesuai dengan kebijakan makro-ekonomi neoliberal.” Institusi menjadi salah satu poin penting dalam format reformasi World Bank. Menurut skema yang diterapkan secara global ini, good governance mengisyaratkan bahwa tata kelola pemerintahan harus dibuat kompatibel dengan mekanisme pasar yang efektif. Untuk menciptakan harmonisasi dengan pasar, berbagai norma pun diperkenalkan, seperti: transparansi, akuntabilitas, dan keterlibatan masyarakat sipil. ${ }^{16}$

Postur normatif dari good governance yang dibingkai oleh aktor institusional justru mengalami transformasi di tengah kondisi tertentu. Dalam Indonesia sendiri telah memperlihatkan betapa rekayasa norma good governance mengalami penyesuaian baru. Sebagai gambaran sederhana, International Monetary Fund (IMF) memberikan bantuan pinjaman melalui berbagai Letter of Intent yang ditandatangani di akhir era kepemimpinan Soeharto. Sementara itu, berbagai institusi lainnya menawarkan bantuan yang sama namun menguatkan wacanagood governance di Indonesia. Gambaran paling sederhana yaitu masifnya kehadiran pendonor seperti Asian Development Bank (ADB). ${ }^{17}$ Tulisan ini melihat adanya program pendalaman atau diskursif yang tiada henti oleh beragam aktor di dalam dinamika ini. Meskipun institusi tersebut berbeda dengan World Bank, namun mereka secara holistik membangun kerangka normatif bersama dengan nama good governance.

Menariknya, hampir semua lembaga donor tersebut melibatkan organisasi masyarakat sipil dalam proses asistensi dengan tujuan memperkuat transparansi dan akuntabilitas pemerintah. Embrio masyarakat sipil di Indonesia sebetulnya sudah mulai muncul ketika pada awal tahun 1990an, organisasi-organisasi non-pemerintah mulai muncul, baik organisasi yang berbasis pada pemberdayaan dan advokasi, keagamaan hingga gerakan-gerakan sosial seperti buruh, petani, sosial-demokrat, dan mahasiswa yang terlibat dalam perlawanan terhadap rezim Soeharto. Selain itu, hadirnya lembaga

16 Neil Brenner, "Good Governance': the ideology of sustainable neoliberalism?" dalam <http://www.bmgev.de/themen/urban21/brenner.htm > diakses 31 Mei 2018.

17 Basuki Agus Suparno \& Arif Wibawa, "Hegemoni Kapitalisme dalam Transisi Demokrasi di Indonesia: Analisis Wacana Kritis” dalam Jurnal Ilmu Komunikasi Vol. 13 No. 3 (2014), h. 215-230. 
pendonor tidak sekedar memberi suntikan dana, melainkan turut mengisi kantongkantong organisasi masyarakat sipil yang berbasis internasional maupun lokal. ${ }^{18}$

Aspinall dan Fealy melakukan penelitian dalam memahami orientasi lembagalembaga donor internasional yang mulai mengarah pada agenda-agenda "assessing democracy assistance" sebagai upaya membangun harmonisasi demokrasi di level negara dan masyarakat. Selanjutnya, Aspinall dan Fealy mengemukakan uraian menarik tentang kaitan antara program demokratisasi Indonesia pasca-Orde Baru dengan peran bantuan institusi internasional. Sehingga, justifikasi mereka bahwa Indonesia adalah negara penerima bantuan yang cukup besar dari lembaga internasional bagi proyekproyek demokrasi.

Bantuan-bantuan dari lembaga internasional seperti USAID, Ford Foundation, Asia Foundation dan beberapa bantuan yang berafiliasi dengan partai politik di negara Eropa seperti Jerman, memperlihatkan peningkatan yang amat drastis. Bantuan tersebut ditujukan baik kepada organisasi masyarakat sipil maupun lembaga-lembaga pemerintah yang dianggap menjadi pilar demokrasi seperti Komisi Pemilihan Umum (KPU), Komnas HAM, Dewan Perwakilan Rakyat (DPR), dan Mahkamah Agung. Bahkan Indonesia merupakan penerima bantuan terbesar dari USAID untuk program demokratisasi. ${ }^{19}$ Perhatian atas proses transisi demokrasi di Indonesia tercermin dari strategi besar yang dicanangkan USAID, yaitu "Making Democratic Governance Deliver."

Dalam pengamatan penulis, terdapat peran penting bahwa negara-negara besar negara yang berfokus mengampanyekan ide demokrasi kapitalisme - dan lembaga internasional dalam memberikan perhatian penting pada enam isu penting terhadap negara berkembang dan miskin, yakni: desentralisasi, pengembangan sistem pemilihan umum, komisi pemilihan, lembaga keamanan dan penegakan hukum, partai politik dan parlemen, masyarakat sipil dan resolusi konflik.

${ }^{18}$ Lembaga pemberi bantuan atas program demokrasi di Indonesia datang baik melalui lembaga multilateral seperti World Bank dan IMF, lembaga pemberi bantuan dari negara-negara besar seperti AUSAID (Australia), USAID (Amerika), LSM internasional dari Eropa seperti Oxfam (Inggris), HIVOS dan NOVIB (Belanda). Disamping itu terdapat pula bantuan yang berafiliasi dengan kekuatan politik di Jerman seperti dari sayap liberal seperti Friederich Naumann Stiftung (FNS) dan dari jalur sosial-demokrat seperti Friedrich Ebert Stiftung (FES). Lembaga Open Society, yang dibentuk oleh pialang saham George Soros, juga merupakan LSM internasional yang menyalurkan bantuan cukup besar untuk program-program LSM demokrasi di Indonesia.Lihat, Edward Aspinall \& G. Fealy, Soeharto's New Order and Its Legacy: Essays in Honour of Harold (Canberra: ANU Press, 2010).

${ }^{19}$ Edward Aspinall, Assessing Democracy Assistance (Brussels: FRIDE, 2010). 
Kehadiran kelompok epistemik memang dibutuhkan dalam proses pengembangan norma internasional seperti good governance. Dalam pandangan neomarxian, Robert Cox menyebutkan bahwa upaya ideasional membutuhkan topangan institusi, sehingga menjadi realitas struktur yang mampu menyusun konteks kebiasaan, tekanan, ekspektasi, dan kekangan-kekangan di mana suatu tindakan berlangsung. ${ }^{20}$ Dalam bentuk paling efisien, maka struktur dapat terbentuk oleh aktifitas dan jejaring kelompok epistemik. Sementara itu, ketika keberlangsungan good governance terjalin maka akan berimplikasi menghadirkan kekuatan masyarakat sipil yang terlegitimasi.

Pada konteks inilah penulis meyakini bahwa menguatnya kelompok-kelompok masyarakat sipil tersebut didesain agar reformasi institusi pemerintah dapat transparan, akuntabel, dan efisien. Dengan norma-norma tersebut tertanam dalam institusi pemerintah, mekanisme pasar dapat berjalan dengan baik tanpa harus dibayang-bayangi oleh monopoli atau korupsi. Artinya, good governance adalah prasyarat dari terciptanya iklim persaingan usaha yang bersih dari intervensi negara - dengan kata lain, neoliberalisme. Melalui penerapan good governance, mekanisme pasar yang dipercaya 'alamiah' dapat berjalan tanpa intervensi politik apapun dari masyarakat. Dalam kondisi ini, posisi masyarakat sipil menjadi jelas, yakni untuk membentuk tata kelola pemerintahan yang kompatibel dengan pasar. Hal inilah yang kemudian membawa kita pada pembentukan kebijakan publik yang semuanya ditujukan untuk kepentingan pasar.

Timo Kivimaki pernah menyatakan bahwa sejak 1 Desember 1997, ketika IMF dan lembaga keuangan dunia lainnya terlibat dalam pemulihan ekonomi di Indonesia, maka Indonesia telah menjadi Republic of $I M F .^{21}$ Istilah yang sarkastis ini digunakan untuk mengilustrasikan betapa lemahnya posisi Indonesia di hadapan institusi keuangan dunia yang mengendalikan mereka melalui beragam persyaratan yang harus ditaati, direviu dan dievaluasi. Hal ini dapat terlihat pada: (a) asumsi perekonomian yang disusun oleh DPR dan Pemerintah Indonesia mengenai Rencana Anggaran Pendapatan dan Belanja Negara (RAPBN) 1998/1999 yang mendapatkan koreksi dari IMF; (b) pertumbuhan ekonomi yang dipatok oleh IMF; (c) tingkat inflasi yang ditentukan oleh IMF; (e) privatisasi BUMN atas permintaan IMF; (e) pembubaran Badan Pemasaran

20 Pandangan Robert Cox telah mengisi beberapa karya akademik dan ditulis ulang dalam buku, George Sorenson, Introduction to International Relations (Oxford: Oxford University Press, 1999).

21 Timo Kivimaki, "Indonesian Relations During the Economic Crisis: Where Has Indonesia's Bargaining Power Gone?” dalam Contemporary Southeast Asia, Vol. 22, No. 3 (2000). h. 527-549. 
Cengkeh berdasarkan kesepakatan dengan IMF; (f) pencabutan subsidi BBM hingga $71 \%$ untuk jenis premium agar lebih sesuai dengan harga pasar.

Berbagai kebijakan publik yang dibuat oleh Pemerintah Indonesia di era Reformasi tidak hanya menunjukkan inferioritas Indonesia dibandingkan lembaga keuangan dunia, namun juga menunjukkan keberpihakan mereka pada agenda neoliberalisme. Kebijakan pemerintah untuk mencabut subsidi BBM menjadi tidak masuk akal jika kita mempertimbangkan fakta bahwa pemerintah masih mensubsidi perbankan hingga Rp 103 triliun sementara subsidi energi hanya sebesar Rp 27 triliun. Sementara rakyat menderita akibat kenaikan harga BBM, perbankan justru menikmati pundi-pundi dana yang tidak lain berasal dari uang pajak rakyat. Lagi-lagi, kebijakan ini ditempuh untuk memenuhi keinginan IMF. ${ }^{22}$

Direktur IMF Michael Camdessus bahkan pernah berkata dengan nada arogan bahwa: "Indonesia tidak mempunyai pilihan apa pun selain menjalankan secara konsisten semua program yang telah disepakati. ${ }^{23}$ Hal bernada sama juga diungkapkan oleh tokoh-tokoh sentral lain dalam poros rezim neoliberalisme. Denis de Tray, Kepala World Bank perwakilan Jakarta menyatakan bahwa tidak ada obat ajaib yang dapat menyembuhkan krisis ekonomi Indonesia. Ia menegaskan bahwa langkah-langkah yang dipreskripsikan IMF merupakan tahapan awal yang harus ditempuh agar dapat "memperoleh kepercayaan kembali".

Ketika Indonesia sudah memenuhi semua persyaratan yang diberikan IMF, yang harus dibayar mahal oleh penderitaan rakyat Indonesia, tokoh-tokoh sentral dalam rezim neoliberalisme bertepuk tangan dan tidak ragu memberikan pujian. Hal ini tercermin dari pernyataan Camdessus:

"Pemerintah Indonesia kini telah menunjukkan komitmennya terhadap paket reformasi yang telah direvisi. Kami terus mengamati bahwa seluruh tindakan pendahuluan seperti yang telah dijanjikan telah dilaksanakan sebelum pertemuan dewan direksi. Jadi saya kini dalam posisi merekomendasikan kepada dewan direksi bahwa hal yang paling tepat adalah mencairkan kontribusi (IMF) untuk Indonesia ${ }^{24}$."

22 Basuki Agus Suparno \& Arif Wibawa, "Hegemoni Kapitalisme dalam Transisi Demokrasi di Indonesia: Analisis Wacana Kritis" dalam Jurnal Imu Komunikasi, Vol. 13 No. 3 (2014). h. 215-230.

${ }^{23}$ Ibid.

${ }^{24}$ Ibid. 
Pujian lain juga datang dari Wakil Menteri Keuangan Amerika Serikat, Lawrence Summers, yang menyatakan bahwa ekonomi Asia Tenggara sudah tidak lagi dalam bahaya. Menurutnya, Indonesia telah mengambil langkah yang tepat untuk mengarah pada pemulihan dan stabilitas. Munculnya pujian-pujian seperti ini menunjukkan bahwa kepentingan-kepentingan mereka telah terpenuhi. Pemerintah Indonesia, dengan mengatasnamakan good governance, telah tunduk kepada rezim neoliberalisme. Dengan demikian, good governance telah merepresentasikan dua makna yang saling berkontradiksi satu sama lain. Di satu sisi, good governance merepresentasikan prinsip-prinsip tata kelola pemerintahan yang menyelamatkan Indonesia dari krisis ekonomi. Namun di sisi lain, good governance juga merepresentasikan rezim neoliberalisme yang menyengsarakan rakyat dengan memaksa Indonesia menerapkan kebijakan-kebijakan liberal. Inilah paradoks good governance di mana mempercayai konsep ini akan menuntut kemampuan Anda melakukan doublethink.

\section{Dampak Buruk Agenda Neoliberalisme dalam Penerapan MP3EI}

"... (it) is not that bad people do bad things - they always do. It's that good people do horrible things thinking they are doing something great." -Slavoj Žižek

Penerapan agenda neoliberalisme dengan kedok good governance di Indonesia pada akhirnya membawa kita pada mega-proyek MP3EI yang merupakan manifestasi utuh atas cengkeraman rezim neoliberalisme di Indonesia dan pengabaian terhadap rakyatnya. Sulit untuk membahas MP3EI tanpa melihat kaitannya dengan krisis finansial global yang melanda dunia pada tahun 2008. Krisis finansial yang melanda jantung kapital global bernama Wall Street tersebut disebabkan oleh fenomena yang disebut dengan over-akumulasi - suatu keadaan di mana terlalu banyak uang yang beredar namun tidak ada lagi ruang yang dapat digunakan untuk mengakumulasi uanguang tersebut.

Fenomena ini telah menghancurkan sirkulasi produksi kapitalisme yang dituntut untuk selalu dan selalu mengakumulasi kapital demi keberlangsungan sistem kapitalisme melalui rumus sederhana: money - commodity - more money. Dalam hal ini, MP3EI merupakan ruang yang dipersiapkan oleh Pemerintah Indonesia bagi ekspansi kapital dari negara-negara yang mengalami krisis finansial agar tidak 
bertumpuk dan memperparah over-akumulasi. Hal semacam ini tentu tidak akan menjadi masalah jika masyarakat mendapatkan keuntungan dari pelaksanaan MP3EI, namun kenyataan berkata lain.

Terdapat dua kata kunci yang harus digarisbawahi dari MP3EI, yakni percepatan dan perluasan. Melalui masterplan ini, Indonesia diharapkan akan mampu mempercepat pengembangan berbagai program pembangunan yang sudah dilaksanakan. Hal ini dinilai akan mendorong peningkatan nilai tambah dari sektor-sektor unggulan, seperti infrastruktur, energi, iptek, dan pembangunan sumber daya manusia. Ke depannya, percepatan pembangunan ini diharapkan akan menunjang pertumbuhan ekonomi Indonesia dan memenuhi ramalan lembaga-lembaga ekonomi internasional yang menyatakan bahwa Indonesia akan menjadi kekuatan ekonomi terbesar ke-4 di dunia pada tahun 2050. Selain percepatan, MP3EI juga mendukung perluasan pembangunan ekonomi agar tidak hanya berpusat di Pulau Jawa saja namun juga dirasakan oleh seluruh komponen masyarakat di seluruh wilayah Indonesia. Semua hal tersebut akan dicapai melalui rencana jangka panjang dengan durasi 15 tahun yang akan merekayasa lanskap perekonomian Indonesia agar kompatibel dengan MP3EI. ${ }^{25}$

Presiden SBY sangat bangga pada realisasi MP3EI, beliau meminta agar megaproyek tersebut dapat diteruskan oleh Presiden Joko Widodo. Menurut SBY, yang mengaku sebagai chief salesperson of Indonesia inc., perkembangan MP3EI sangat menggembirakan karena mayoritas proyek dilakukan di luar pulau Jawa dengan nilai total mencapai Rp 544 triliun. Lebih lanjut, beliau menyatakan kebanggannya terhadap keberadaan bandara mewah di Bali, Balikpapan, Medan, dan Makassar, begitu pula dengan jalan tol atas laut yang dapat dinikmati di Bali. Menurut SBY, semua hal ini akan memacu kegiatan ekonomi masyarakat ${ }^{26}$. Presiden SBY begitu mempercayai betapa baiknya kebijakan yang ia rumuskan, beliau tidak menyadari banyaknya dampak-dampak buruk yang dihasilkan oleh MP3EI. Dalam hal ini, laporan yang dibuat

\footnotetext{
${ }^{25}$ Kementerian Koordinator Bidang Perekonomian. Masterplan Percepatan dan Perluasan Pembangunan Ekonomi Indonesia. (Jakarta: Kementerian Koordinator Bidang Perekonomian, 2014).

26 Tempo, "SBY Banggakan Realisasi MP3EI" dalam, https://m.tempo.co/read/news/2014/08/15/090599864/sby-banggakan-realisasi-mp3ei / diakses 31 Mei 2018.
} 
oleh Sajogyo Institute menyebutkan bahwa apa yang dipercepat dan diperluas oleh MP3EI bukanlah pembangunan melainkan krisis sosial-ekologis. ${ }^{27}$

Sajogyo Institute melaporkan bahwa desain pembangunan MP3EI merupakan desain yang hanya diperuntukkan bagi dunia bisnis dan pemilik korporasi raksasa ${ }^{28}$. Sejumlah kepentingan pebisnis dan korporasi berhasil terakomodir melalui MP3EI, seperti kemudahan untuk melakukan investasi di Indonesia. Dalam hal ini, Indonesia dianggap sebagai salah satu pusat produksi di dunia yang memiliki nilai lebih berupa populasi tenaga kerja yang besar dan murah. Untuk menyukseskan jejaring produksi global, Indonesia harus membuka diri terhadap modal-modal asing untuk membangun industri-industri yang akan mempekerjakan buruh-buruh Indonesia ${ }^{29}$. Hal ini tercermin dengan jelas dari pidato pembukaan Presiden SBY dalam pertemuan CEO APEC pada tahun 2013 di mana beliau menyatakan: "Saya (Presiden Indonesia) mengundang Anda untuk memperbesar bisnis dan kesempatan investasi di Indonesia ${ }^{30,}$, Dengan demikian, janji-janji pertumbuhan ekonomi dan peningkatan lapangan pekerjaan yang diberikan oleh MP3EI harus dipahami bukan sebagai upaya Pemerintah Indonesia mensejahterakan rakyatnya melainkan upaya untuk memenuhi kepentingan rezim neoliberalisme global.

Di bawah MP3EI, Indonesia seolah dipaksa untuk menyadari posisinya dalam pembagian kerja ekonomi internasional dan mengoptimasikan posisinya tersebut dengan cara mengeksploitasi segala sumber daya yang mereka miliki, mulai dari lahan hingga pekerja. Naskah MP3EI menyebutkan bahwa megaproyek ini berlandaskan pada tiga pilar: (1) pembangunan ekonomi; (2) pembangunan sosial; dan (3) kelestarian perlindungan lingkungan. Akan tetapi, dengan melihat realita selama pelaksanaan MP3EI, Rachman berargumen bahwa tiga pilar utama MP3EI yang sesungguhnya

${ }^{27}$ Noer Fauzi Rachman, "Master Plan Percepatan dan Perluasan Krisis Sosial-Ekologis Indonesia", dalam http://www.aman.or.id/wp-content/uploads/2014/06/Rachman-2014-MP3EI-AMAN1.pdf diakses 31 Mei 2018.

28 Studi ini dilakukan oleh Dian Januardi, Noer Fauzi Rahmanda, dan Mia Siscawati dengan judul “ Proses-proses Kebijakan dan Konsekuensi dari MP3EI”. Riset ini diselenggarakan oleh lembaga studi Sajogyo Institute. Hasil riset ini lantas dipublikasikan oleh Aliansi Masyarakat Adat Nusantara (AMAN). Lebih lanjut, unduh http://www.aman.or.id/wp-content/uploads/2014/06/Rachman-2014-MP3EI-AMAN1.pdf

${ }^{29}$ R. Dhaifan Surya Saputra, Analisis Wacana Pidato Presiden SBY dalam Acara Peluncuran Masterplan Percepatan Perluasan Pembangunan Ekonomi Indonesia 2011-2025. (Malang: Universitas Muhammadiyah Malang, 2011).

30 Susilo Bambang Yudhoyono, "Opening Speech President Yudhoyono at APEC CEO Summit 2013” dalam http://www.apec2013ceosummit.com/coverage/opening-speech-president-yudhoyono-at-apecceo-summit-2013.html diakses 19 Juli 2018. 
adalah (1) konsesi sumber daya alam skala luas; (2) pembentukan kawasan ekonomi khusus; dan (3) pembangunan proyek-proyek infrastruktur. Pilar pertama, konsesi sumber daya alam, dilaksanakan dengan pemberian lisensi-lisensi, khususnya di sektor pertambangan, perkebunan, dan kehutanan kepada perusahaan-perusahaan multinasional untuk memproduksi beragam komoditas yang dibutuhkan pasar global. ${ }^{31}$ Ekstraksi sumber daya alam dengan skala masif ini ditunjang oleh pilar kedua, pembentukan kawasan ekonomi khusus, yang memberikan keistimewaan-keistimewaan bagi pelaku bisnis di kawasan tersebut.Sementara itu, pilar ketiga, pembangunan infrastruktur, dilakukan dengan tujuan mengurangi jarak waktu dalam perpindahan barang, komoditas, uang, dan tenaga kerja, untuk menunjang bisnis-bisnis di kawasan ekonomi khusus.

Permasalahan dari MP3EI menjadi begitu kentara dengan munculnya berbagai perlawanan berbasis agraria terhadap kebijakan-kebijakan pembangunan yang dilaksanakan di bawah kerangka MP3EI. Perlawanan agraria ini mulai muncul semenjak pecahnya kasus PT. Weda Bay Nickel dan Merauke Integrated Food and Energy Estate (MIFEEE) di mana pihak perusahaan diberitakan berkonflik dengan masyarakat adat setempat karena dinilai belum mengantongi izin $^{32}$. Di sini para lembaga swadaya masyarakat (LSM) melihat bahwa pemerintah Indonesia telah memberikan izin pembukaan lahan bagi perusahaan tanpa meminta persetujuan terlebih dahulu dari masyarakat adat setempat.Pembangunan Kawasan Ekonomi Khusus (KEK) melalui MP3EI telah memberikan otoritas tanpa batas kepada pemerintah lokal untuk berinteraksi langsung dengan pemodal terkait izin pembukaan lahan usaha.Permasalahannya, para LSM menilai bahwa pemerintah lokal tidak merepresentasikan kepentingan masyarakatnya. ${ }^{33}$

Dengan munculnya kasus-kasus sepertidi atas selama pelaksanaan MP3EI, LSM-LSM di Indonesia menyimpulkan bahwa MP3EI telah mengesampingkan hak rakyat atas tanah mereka demi melaksanakan pembangunan.Di sinilah muncul berbagai

${ }^{31}$ Noer Fauzi Rachman, loc.cit.

32 Mongabay, "6 Perusahaan Sawit Cemari Sungai di Merauke" dalam http://www.mongabay.co.id/2012/12/25/6-perusahaan-sawit-cemari-sungai-di-merauke/ diakses 19 Juli 2018.

33 Konsorsium Pembaruan Agraria, "Perjuangan Tanah-Air Menghadapi Model Pembangunan Ekonomi Neo-Kolonial” dalam http://www.kpa.or.id/news/organisasi /dokumen/undangundang/perjuangan-tanah-air-menghadapi-model-pembangunan-ekonomi-neo-kolonial/ diakses 19 Juli 2018. 
wacana yang membingkai MP3EI sebagai "Model Pembangunan Ekonomi NeoKolonial." Istilah "Neo-Kolonial" membangkitkan imaji akan sejarah panjang penjajahan Belanda di Indonesia di mana tanah-tanah di Indonesia dirampas demi kepentingan pemerintah kolonial. Perbedaannya, penjajahan di bawah MP3EI tidak dilaksanakan oleh negara lain melainkan negara sendiri.Melalui strategi pembingkaian ini, LSM-LSM di Indonesia berhasil membangkitkan kesadaran masyarakat-masyarakat lokal untuk melawan segala bentuk proyek pembangunan yang dilaksanakan berdasarkan skema MP3EI.

Salah satu wujud nyata dari keberhasilan strategi ini adalah diadakannya Konsorsium Pembaruan Agraria (KPA) bertajuk "Perjuangan Tanah-Air Menghadapi Model Pembangunan Ekonomi Neo-Kolonial” pada tahun $2013^{34}$. Sekitar 19 LSM yang bergerak di bidang perlindungan masyarakat adat, pelestarian lingkungan, penegakkan HAM, dan emansipasi perempuan tergabung dalam KPA untuk menghasilkan sebuah teks perlawanan terhadap MP3EI.

Upaya perlawanan terhadap permasalahan agraria yang ditimbulkan oleh pelaksanaan MP3EI di Indonesia kemudian mendapat nafas baru dengan munculnya argumen mengenai pelanggaran HAM. LSM Kontras merupakan salah satu yang paling vokal dalam upaya ini, mereka melihat bahwa pelanggaran hak ekologi yang diakibatkan oleh MP3EI merupakan bagian dari pelanggaran $\mathrm{HAM}^{35}$. Tidak hanya itu, Kontras juga berhasil menggaet LSM International Federation for Human Rights (FIDH) yang berbasis di Perancis untuk merilis sebuah laporan bertajuk "Indonesia: No Development without Rights" pada tahun 2014.

Dalam laporan tersebut, FIDH dan Kontras (2014) menyebutkan bahwa absennya kerangka hukum yang jelas mengenai hak agraria telah mengakibatkan sejumlah warga Indonesia kehilangan hak atas tanah tempat mereka berproduksi dan juga lingkungan yang nyaman untuk ditinggali. Mereka juga menyebutkan bahwa situasi ini telah berkembang menjadi konflik serius yang melibatkan kekerasan antara warga dan perusahaan. Tidak hanya itu, terdapat juga banyak kasus di mana warga Indonesia mendapati dirinya dikriminalisasi hanya karena mengklaim hak mereka atas tanah tempat mereka tinggal. Seluruh permasalahan ini membuat Kontras dan FIDH

\footnotetext{
${ }^{34}$ Ibid.

${ }^{35}$ Febrian, loc.cit.
} 
berkesimpulan bahwa skema pembangunan melalui MP3EI telah mengakibatkan pelanggaran-pelanggaran HAM yang serius.

Berbagai perlawanan di atas membuktikan bahwa dibalik proyek pembangunan, percepatan dan perluasan ekonomi, masih banyak kalangan masyarakat yang termarjinalkan.Karena bagi mayoritas warga, beberapa capaian infrastruktur MP3EI justru berdampak pada penyempitan ruang untuk hidup dengan layak, bahkan berdampak pada hilangnya "kampung halaman ${ }^{36}$."Ruang hidup layak di sekitar wilayah yang kaya SDA semakin menyempit, pencemaran lingkungan akibat limbah pabrik ataupun limbah proyek semakin menyebar, tanah menjadi tidak subur, dan dampak negatif lain dari pembangunan infrastruktur yang tidak dipertimbangkan ${ }^{37}$. Satu hal yang jarang diperbincangkan adalah ruang hidup layak bagi warga kota yang juga terus menyempit akibat penguasaan lahan untuk kepentingan bisnis properti yang juga dilaksanakan di bawah MP3EI. ${ }^{38}$

Apa yang terjadi di balik MP3EI adalah jerit tangis warga-warga Indonesia yang terusir dari rumahnya tanpa mendapatkan kompensasi. Di balik peningkatan lapangan kerja terdapat penderitaan buruh-buruh Indonesia yang dieksploitasi dengan upah yang jauh lebih rendah dari nilai kerja yang mereka hasilkan. Di balik kue ekonomi Indonesia yang semakin besar, tersembunyi ketimpangan yang semakin melebar antara orang kaya dan miskin. Presiden SBY memutuskan penyelenggaraan MP3EI karena mempercayainya sebagai hal yang baik bagi Indonesia, namun justru menimbulkan bencana sosial-ekologis yang semakin parah dari hari ke hari. Semua itu karena beliau menerapkan agenda neoliberalisme melalui MP3EI.

\section{Penutup}

Negara maju telah meletakkan good governance ke negara berkembang sebagai konsolidasi neoliberalisme. Beberapa agendanya dimulai dari institusi sebagai agen yang mempromosikan wacana tersebut. IMF, World Bank dan ADB adalah tiga institusi yang paling nyata memperlihatkan upaya pengarusutamaan good governace di

36 Tito, loc.cit.

37 Mongabay, "Komnas HAM: MP3EI, Program Pembangunan Abai HAM" dalam http://www.mongabay.co.id/2014/07/01/komnas-ham-mp3ei-program-pembangunan-abai-ham/diakses, 19 Juli 2018.

38 Fathimah Fildzah Izzati, "Pembangunan dan Perebutan Ruang Kota" dalam https://indoprogress.com/2013/06/pembangunan-dan-perebutan-ruang-kota/ diakses 19 Juli 2018. 
Indonesia dengan desain bantuan-bantuan finansial. Sejumlah persyaratan yang dirancang berbagai lembaga pemberi bantuan tersebut harus dilihat sebagai upaya rezim neoliberal melakukan sosialisasi nilai-nilai yang mereka kehendaki kepada aktor di luar dirinya, seperti Indonesia di awal Reformasi. Fase pendalaman neoliberalisme melalui wacana tadi, justru tidak diikuti dengan pendalaman demokrasi di Indonesia. Indonesia terlihat sibuk menjalankan berbagai desain neoliberalisme seperti MP3EI. Akibatnya tuntutan-tuntutan mendasar bagi demokrasi subtansial kehilangan arah. Paradoks good governance pada akhirnya menyebabkan pemerintah yang seharusnya mengutamakan kepentingan rakyatnya justru mengorbankan mereka demi menunjukkan loyalitas kepada rezim neoliberalisme.

Dalam perkembangan terkini, konsep good governance terus mengalami perkembangan agar semakin dapat diterima oleh khalayak umum. Akibat kritik-kritik terhadap konsep good governance yang dinilai terlalu mengutamakan pembangunan makroekonomi dan pertumbuhan ekonomi dibandingkan pembangunan sosial, rezim neoliberalisme global kemudian memperkenalkan Sustainable Development Goals (SDGs) di tahun 2015 yang mengikutsertakan aspek sosial sebagai salah satu elemen utama dalam good governance. Akan tetapi, analisis diskursus terhadap SDGs telah menemukan bahwa aspek sosial dalam SDGs hanya digunakan untuk menjustifikasi kepentingan pertumbuhan ekonomi ${ }^{39}$. Hal ini tercermin dari penetapan Addis Ababa Action Agenda (AAAA) sebagai kerangka pembiayaan pelaksanaan program-program SDGs yang memungkinkan sektor bisnis untuk menentukan arah dari program "pembangunan berkelanjutan" di tingkat global ${ }^{40}$. Hal ini mengindikasikan bahwa agenda good governance di tingkat global tetap mengutamakan kepentingan pemilik kapital terkait pertumbuhan ekonomi di atas segalanya.

Sementara itu di Indonesia, pola penguasaan lahan melalui skema pembangunan nasional, entah PELITA di era Orde Baru dan MP3EI di era Reformasi, tetap bertahan.Pergantian rezim kepemimpinan di Indonesia hanya mengubah narasi pembangunan nasional dari modernisasi menjadi good governance, namun keduanya

${ }^{39}$ Viktoria Spaiser, et. al, “The Sustainable Development Oxymoron: Quantifying And Modelling The Incompatibility Of Sustainable Development Goals" dalam International Journal of Sustainable Development \& World Energy, Vol. 24, No. 6 (2017), h. 457-470.

${ }^{40}$ Global Policy Watch, "Civil Society Response to the Addis Ababa Action Agenda on Financing for Development” dalam https://www.globalpolicywatch.org/wp-content/uploads/2015/07/20150716CSO-Response-to-FfD-Addis-Ababa-Action-Agenda.pdf diakses 16 Juli 2015. 
sama-sama menyembunyikan fakta bahwa pembangunan nasional tidak dilaksanakan untuk kesejahteraan masyarakat Indonesia melainkan untuk kepentingan pertumbuhan ekonomi semata. Demi mewujudkan pertumbuhan ekonomi, rakyat boleh dimarjinalkan sementara pemerintah Indonesia dapat mengklaim keberhasilan pembangunan dengan menunjukkan statistik dan infrastruktur yang berhasil terbangun.

Pola serupa juga terlihat dalam kepemimpinan Presiden Joko Widodo yang, meskipun tidak menggunakan nama MP3EI, tetap mengutamakan pembangunan berdasarkan: (1) konsesi sumber daya alam skala luas (mis. pemanfaatan sumber daya laut, termasuk gas alam, melalui Poros Maritim); (2) pembentukan kawasan ekonomi khusus; dan (3) pembangunan proyek-proyek infrastruktur (mis. percepatan pembangunan jalan tol lintas-provinsi menjelang Pilpres 2019). Pada kenyataannya, pidato Presiden SBY dalam APEC CEO Summit 2013 juga digemakan kembali oleh Presiden Jokowi dalam APEC CEO Summit 2014 dengan menyatakan bahwa "Kami (Pemerintah dan Rakyat Indonesia) menunggu Anda untuk datang ke Indonesia. Kami menunggu Anda untuk berinvestasi di Indonesia ${ }^{41}$."Kemungkinan terburuk yang dapat ditimbulkan dari seluruh situasi ini adalah bahwa pembangunan nasional tidak hanya digunakan sebagai instrumen neoliberalisme untuk meningkatkan akumulasi kapital namun juga instrumen populis untuk mengangkat pamor seorang kepala negara dengan mengorbankan kepentingan rakyat.

Pada akhirnya, dapat disimpulkan bahwa tidak ada perubahan mendasar dari pembangunan nasional Indonesia sebelum dan sesudah Reformasi. Pembangunan nasional pasca-Reformasi yang dilaksanakan atas dasar "komitmen terhadap Good Governance" tetap hanya mengutamakan kepentingan pemilik modal dan pertumbuhan ekonomi dibandingkan kesejahteraan rakyat Indonesia.

Konsep Good Governance menjadi paradoks karena meskipun dibalut dengan kata 'baik (Good)', nyatanya menimbulkan banyak 'mudarat (Bad)' bagi masyarakat yang seharusnya menjadi penerima manfaat dari tata kelola yang 'baik' ini. Daripada menciptakan sebuah pemerintahan yang lebih baik dan demokratis, good governance justru mempertahankan pola-pola kediktatoran namun dengan cara yang lebih halus dan

41 Jokowi Widodo, "Full Speech: Jokowi at APEC CEO Summit 2014" dalam https://www.rappler.com/world/regions/asia-pacific/indonesia/74620-full-speech-joko-widodo-apecsummit-beijing diakses 20 Juli 2018. 
mendisiplinkan (governmentality) serta tidak terpikirkan oleh mereka yang terpesona oleh sosok pemimpin populer.

\section{DAFTAR PUSTAKA}

Abrahamsen, Rita. Disciplining Democracy: Development Discourse and Good Governance in Africa. London: Zed Books, 2000.

Al-Bassam, Bassam A. "The Relationship Between Governance and Economic Growth During Times of Crisis" dalam European Journal of Sustainable Development 2, No. 4 (2013), h. 1-18.

Andrews, Matt. "The Good Governance Agenda: Beyond Indicators without Theory" dalam Oxford Development Studies 36, No. 4 (2008), h. 379-407.

Apaza, Carmen. "Measuring Governance and Corruption through the Worldwide Governance Indicators: Critiques, Responses, and Ongoing Scholarly Discussion” dalam Political Science and Politics 42, No. 1 (2009), h. 139 - 143.

Aspinall, Edward, dan G. Fealy. Soeharto's New Order and Its Legacy: Essays in Honour of Harold. Canberra: ANU Press, 2010.

Aspinall, Edward. Assessing Democracy Assistance. Brussels: FRIDE, 2010.

Booth, David. "Aid, Institutions and Governance: What Have We Learned?" dalam Development Policy Review 29, No. 1 (2010), h. 5-26.

Brenner, Neil. "'Good Governance': the ideology of sustainable neoliberalism?" dalam http://www.bmgev.de/themen/urban21/brenner.htm/ diakses 31 Mei 2017.

Chandler, David. "Good Governance Can Make Bad Government: A study of Iinternational Anti-Corruption Initiatives in Bosnia-Herzegovina" dalam Good Governance in the Era of Global Neoliberalism, oleh Jolle Demmers, Alex E.Fernández Jilberto dan Barbara Hogenboom. London: Routledge, 2004.

Dirhantoro, Tito. "MP3EI Timbulkan Masalah hingga ke Daerah" dalam http://geotimes.co.id/mp3ei-timbulkan-masalah-hingga-daerah/ diakses 16 Mei 2017.

Fayissa, Bichaka \& Christian Nsiah. "The Impact of Governance on Economic Growth in Africa" dalam The Journal of Developing Areas 47, No. 1 (2013), h. 91-108.

Febrian. "Kontras: MP3EI Dapat Berdampak pada Pelanggaran HAM" dalam http://nasional.kompas.com/read/2014/06/12/1635570/Kontras.MP3EI.Dapat.Be rdampak.pada.Pelanggaran.HAM/ diakses 16 Mei 2017. 
FIDH \& Kontras. "Indonesia: No Development without Rights" dalam https://tbinternet.ohchr.org/Treaties/CESCR/Shared\%20Documents/IDN/INT_C ESCR_CSS_IDN_17094_E.pdf / diakses 16 Mei 2017.

Foucault, Michael. The Archaeology of Knowledge. London: Routledge, 1991.

Fukuyama, Francis. "The End of History?" dalam The National Interst, No.16 (1989), h. 3-18.

Gisselquist, Rachel M. "Good Governance as a Concept, and Why This Matters for Development Policy" dalam WIDED Working Paper, No. 30 (2012), h. 1-36.

Global Policy Watch. "Civil Society Response to the Addis Ababa Action Agenda on Financing for Development" dalam https://www.globalpolicywatch.org/wpcontent/uploads/2015/07/20150716-CSO-Response-to-FfD-Addis-AbabaAction-Agenda.pdf/ diakses 20 Juli 2018.

Hadiz, Vedi dan Richard Robison. Reorganising Power in Indonesia: The Politics of Oligarchy in an Age of Markets. London: Routledge, 2004.

IMF. Good Governance: The IMF's Role. Washington DC: IMF, 1997.

Izzati, Fathimah Fildzah. "Pembangunan dan Perebutan Ruang Kota" dalam https://indoprogress.com/2013/06/pembangunan-dan-perebutan-ruang-kota/ diakses 19 Juli 2018.

Jenkins, Rhys. "Structural Adjustment and Bolivian Industry" dalam The European Journal of Development Research, Vol. 9 Issue 2 (1997), h. 107-128.

Jilberto, Alex E. Fernandes. "The Political Economy of Neoliberal Governance in Latin America: The Case of Chile" dalam Good Governance in the Era of Global Neoliberalism, oleh Jolle Demmers, Alex E.Fernández Jilberto dan Barbara Hogenboom, 33-55. London: Routledge, 2004.

Kaufmann, Daniel, Aart Kraay \& Pablo Zoido-Lobaton. "Governance Matters" dalam World Bank Policy Research Working Paper No. 2196 (1999).

Keefer, Philip. "Governance" dalam The SAGE Handbook of Comparative Politics , oleh Todd Landman dan Neil Robinson, 439-462. London: Sage, 2009.

Kementerian Koordinator Bidang Perekonomian. Masterplan Percepatan dan Perluasan Pembangunan Ekonomi Indonesia. Jakarta: Kementerian Koordinator Bidang Perekonomian, 2014.

Kivimaki, Timo. "U.S.--Indonesian Relations During the Economic Crisis: Where Has Indonesia's Bargaining Power Gone?" dalam Contemporary Southeast Asia, Vol. 22, No. 3 (2000), h. 527-549. 
KPA. "Perjuangan Tanah-Air Menghadapi Model Pembangunan Ekonomi NeoKolonial” dalam http://www.kpa.or.id/news/organisasi/dokumen/undangundang/perjuangan-tanah-air-menghadapi-model-pembangunan-ekonomi-neokolonial/ diakses 19 Juli 2018.

Lindblad, J. Thomas. "The Economic Decolonisation of Indonesia: a Bird's-eye View" dalam Journal of Indonesian Social Sciences and Humanities Vol. 4 (2011), h. $1-20$.

Manners, Ian. "Normative Power Europe: A Contradiction in Terms" dalam Journal of Common Market Studies, Vol. 40, No.2 (2002), h. 235-258.

Mkandawire, Thandike. "Good Governance: The Itinerary of an Idea" dalam Development in Practice, Vol. 17, No 4/5 (2007), h. 679-681.

Mongabay. "6 Perusahaan Sawit Cemari Sungai di Merauke”. 25 Desember 2012. http://www.mongabay.co.id/2012/12/25/6-perusahaan-sawit-cemari-sungai-dimerauke/ diakses 19 Juli 2018.

Mongabay. "Komnas HAM: MP3EI, Program Pembangunan Abai HAM" dalam http://www.mongabay.co.id/2014/07/01/komnas-ham-mp3ei-programpembangunan-abai-ham/ diakses 19 Juli 2018.

Mongabay. "Weda Bay Nickel, Berkonflik dengan Masyarakat Adat, Hutan Lindung pun Terancam" dalam http://www.mongabay.co.id/2013/06/07/weda-baynickel-berkonflik-dengan-masyarakat-adat-hutan-lindung-pun-terancam/ diakses 19 Juli 2018.

Nanda, Ved P. "The "Good Governance" Concept Revisited" dalam The Annals of the American Academy of Political and Social Science, 603 (2006), h. 269-283.

Oman, Christiane Arndt \& Charles. Uses and Abuses of Governance Indicators. Paris: OECD Development Center, 2006.

Rachman, Noer Fauzi. "Master Plan Percepatan dan Perluasan Krisis Sosial-Ekologis Indonesia" dalam http://www.aman.or.id/wp-content/uploads/2014/06/ Rachman-2014-MP3EI-AMAN1.pdf / diakses 31 Mei 2017.

Rahman, Arif Budi. "Good Governance: Challenge and Prospect for Indonesia." Widyariset Vol. 14 No. 1 (2011), h. 83-92.

Rose, N. Powers of Freedom: Reframing Political Thought. Cambridge: Cambridge University Press, 1999. 
Schiavo, Lidia Lo \& Pierre Vercauteren. "Good Governance, Neoliberalism, Inequality within the International Organization Discourse: a Critical Approach" dalam http://paperroom.ipsa.org/papers/paper_53391.pdf/ diakses 31 Mei 2017.

SDGs - United Nation. "Good Governance in Sustainable Development" dalam https://sustainabledevelopment.un.org/partnership/?p=1545/ diakses 20 Juli 2018.

Soetadi, R. Dhaifan Surya Saputra. Analisis Wacana Pidato Presiden SBY dalam Acara Peluncuran Masterplan Percepatan Perluasan Pembangunan Ekonomi Indonesia 2011-2025. Malang: Universitas Muhammadiyah Malang, 2012.

Sorenson, George. Introduction to International Relations. Oxford: Oxford University Press, 1999.

Spaiser, Viktoria, Shyam Ranganathan, Ranjula Bali Swain \& David Sumpter. "The Sustainable Development Oxymoron: Quantifying And Modelling The Incompatibility Of Sustainable Development Goals" dalam International Journal of Sustainable Development \& World Energy, Vol. 24, No. 6 (2016), h. 457-470.

Supardi, Teddy Firman. "Pembangunan dan Perencanaan Pembangunan: Kritik Pembangunan atas Perencanaan Pembangunan Master Plan Percepatan Perluasan Ekonomi Indonesia (MP3EI)" dalam https://www. academia.edu /11015071/MP3EI_Pembangunan_atau_pemiskinan_/diakses 31 Mei 2017.

Suparno, Basuki Agus. "Hegemoni Kapitalisme dalam Transisi Demokrasi di Indonesia: Analisis Wacana Kritis" dalam Jurnal Ilmu Komunikasi, Vol. 13, No. 3 (20140, h. 215-230.

Tempo. "SBY Banggakan Realisasi MP3EI" dalam https://m.tempo.co/read/news /2014 /08/15/090599864/sby-banggakan-realisasi-mp3ei / diakses 31 Mei 2017.

Thomas, M.A. "What Do the Worldwide Governance Indicators Measure?" dalam The European Journal of Development Research, Vol.22, No. 1 (2010), h. 31-54.

Thorsen, Dag Einar \& Amund Lie. "What is Neoliberalism?" dalam http://folk.uio.no/ daget/neoliberalism.pdf / diakses 8 April 2017.

UNDP. Deepening Democracy in Fragmented World. New York: UNDP, 2002.

UNDP. Human Development Report 2002: Deepening Democracy in a Fragmented World. New York: UNDP, 2002.

United Nations. Report of the Secretary-General on the Work of the Organization. New York: United Nations, 1999. 
Widodo, Joko. "FULL SPEECH: Jokowi at APEC CEO Summit 2014" dalam https://www.rappler.com/world/regions/asia-pacific/indonesia/74620-fullspeechjoko-widodo-apec-summit-beijing/ diakses 20 Juli 2018.

World Bank. "World Bank Approves New Financing for Priority Reforms in Indonesi" dalam http://www.worldbank.org/en/news/press-release/2012/11/20/world-bankapproves-new-financing-priority-reforms-indonesia / diakses 16 Mei 2017.

World Bank. Governance and Development. Washington DC: World Bank, 1992.

World Bank. Sub-Saharan Africa. From Crisis to Sustainable Growth: A Long-Term Perspective Study. Washington DC: World Bank, 1989.

Yudhoyono, Susilo Bambang. "Opening Speech President Yudhoyono at APEC CEO Summit 2013" dalam http://www.apec2013ceosummit.com/coverage/openingspeech-president-yudhoyono-at-apec-ceo-summit-2013.html/ diakses 19 Juli 2018. 